\title{
Enhancing Fatigue Performance of Sandwich Composites with Nanophased Core
}

\author{
S. Zainuddin, ${ }^{1}$ H. Mahfuz, ${ }^{2}$ and S. Jeelani' ${ }^{1}$ \\ ${ }^{1}$ Center for Advanced Materials (T-CAM), Tuskegee University, Tuskegee, AL 36088, USA \\ ${ }^{2}$ Department of Ocean and Mechanical Engineering, Florida Atlantic University, Boca Raton, FL 33431, USA
}

Correspondence should be addressed to H. Mahfuz, hmahfuz@fau.edu

Received 27 October 2009; Accepted 31 March 2010

Academic Editor: Gaurav Mago

Copyright ( 2010 S. Zainuddin et al. This is an open access article distributed under the Creative Commons Attribution License, which permits unrestricted use, distribution, and reproduction in any medium, provided the original work is properly cited.

\begin{abstract}
We report fatigue performance of sandwich composites with nanophased core under shear load. Nanophased core was made from polyurethane foam dispersed with carbon nanofiber (CNF). CNFs were dispersed into part-A of liquid polyurethane through a sonication process and the loading of nanoparticles was $1.0 \mathrm{wt} \%$. After dispersion, part-A was mixed with part-B, cast into a mold, and allowed to cure. Nanophased foam was then used to fabricate sandwich composites. Static shear tests revealed that strength and modulus of nanophased foams were $33 \%$ and $19 \%$ higher than those of unreinforced (neat) foams. Next, shear fatigue tests were conducted at a frequency of $3 \mathrm{~Hz}$ and stress ratio (R) of 0.1 . S-N curves were generated and fatigue performances were compared. Number of cycles to failure for nanophased sandwich was significantly higher than that of the neat ones. For example, at $57 \%$ of ultimate shear strength, nanophased sandwich would survive 400,000 cycles more than its neat counterpart. SEM micrographs indicated stronger cell structures with nanophased foams. These stronger cells strengthened the sub-interface zones underneath the actual core-skin interface. High toughness of the sub-interface layer delayed initiation of fatigue cracks and thereby increased the fatigue life of nanophased sandwich composites.
\end{abstract}

\section{Introduction}

In most of the applications, sandwich beams are subjected to repetitive transverse loading. Because of this, sandwich beams constituents are subjected to a variety of loading situations. The face sheets exhibit membrane tension/compression behavior, and the core undergoes the most critical stress, that is, pure shear [1]. The most common failure of sandwich construction is the core shear failure that occurs when the shear stress reaches its critical value [2]. Many researchers have studied sandwich structures emphasizing face sheets, and it is generally agreed that behavior of face sheets is well known. On the other hand, comparatively less has been done to study the core behavior of sandwich structures. It has been demonstrated over time $[3,4]$ that during flexural or shear loading, core basically controls the failure and is first to fail. Studies $[5,6]$ on the flexural behavior of foam core sandwiches showed that numerous cracks are initiated in the core sub-interface area. These cracks grow together and propagated on the compression side of the beam, immediately below the subinterface. Cracks propagate parallel to the beam up to a short length, then kink into core, and proceed as core shear until it reaches the sub-interface zone on the tension side of the specimen. Shipsha et al. [7] performed tests on H100 foams and found that crack continuously propagated along the interface in the core material below the resin rich cells with diagonal secondary fracture cracks. In all these cases, core shear stresses produced global deformation. Therefore it will be highly beneficial to enhance the core material properties which can offer high resistance to failure.

Recent advances in nanocomposites showed significant improvement in mechanical and thermal properties [811]. One additional advantage in nanocomposites is that in order to achieve these enhancements, it requires only a small wt $\%$, typically $1-3 \mathrm{wt} \%$, loading of nanoparticles $[12,13]$. Experimental results of nanophased composites have shown significant increase in strength and modulus $[5,14,15]$ and decrease in permeability, flammability, and shrinkage [16-18]. One of the present authors also showed 
that by infusing a small percentage of nanoparticles in the foam, the static properties of sandwich structures can also be enhanced under flexural loading [19]. Similar trend has been demonstrated when nanophased sandwich structures were tested under compression and high strain rate loadings [20].

As far as particles are concerned, vapor-grown carbon nanofibers (CNFs) are drawing significant attention due to their high strength, modulus, and relatively low cost $[21,22]$. These particles are synthesized from pyrolysis of hydrocarbon or carbon monoxide in the gaseous state, in presence of a catalyst $[23,24]$. As opposed to carbon nanotubes (CNTs), CNFs do not have tubular structure-rather they have carbon fiber-like structure with diameter in the nanometer range and a good aspect ratio. Carbon nanofibers have been used in this investigation as reinforcement. One of the main reasons to use CNF as reinforcement was of course the cost but more than that was the acicular aspect of CNF. Carbon nanofibers having large aspect ratio would allow more entanglement with polymer chains at the mesophase stage of the foaming process. This entanglement of CNFs with the polymer would introduce interfacial tension when stresses are applied and allow large deformation-a property that would be desirable under shear and fatigue loading.

Uniform dispersion of nanoparticles poses another problem in the preparation of nanocomposites. Due to high surface energy, nanoparticles tend to agglomerate and produce unwanted stress concentration which may act as a precursor for failure. High-intensity ultrasonic waves have been used successfully to get uniform dispersion of nanoparticles [25, 26]. Ultrasound waves generate nonlinear effects in the liquid, namely transient cavitation and acoustic streaming [27-30]. Acoustic cavitation involves formation, growth, pulsating, and collapsing of minute bubbles, producing transient (in the order of microseconds) microhot spots that can reach temperatures of about $5000^{\circ} \mathrm{C}$, pressure of about $1000 \mathrm{~atm}$, and heating and cooling rates above $1010 \mathrm{~K} / \mathrm{s}$ [31]. Strong acoustic impact coupled with local high temperature effects accelerates intrinsic mixing of polymer and nanoparticles and can break the agglomerated particles by damaging the Coulomb and Van der Waals forces resulting in a homogenous dispersion.

Mechanical behavior of foam cores for simple stress states such as uniaxial tension or compression has been studied extensively [32-35]. Only a limited number of investigations have dealt with multiaxial behavior [36, 37]. In this study, polyurethane foam properties have been modified by dispersing nanoparticles through sonic cavitation. Sandwich panels were then fabricated using the nanophased foam as core materials through the CIRTM process. In parallel, control sandwich panels were also made using neat polyurethane foam. Response of these sandwich structures under static and cyclic shear loading are described in the paper.

\section{Materials and Manufacturing of Sandwich Composites}

Materials used for making two categories of sandwich composites are shown in Table 1. The manufacturing of panels was carried out in three steps; the first was the dispersion of nanoparticles into liquid polyurethane, the second was casting of the foam (core materials), and the final was fabrication of sandwich panels using CIRTM. In addition, a number of sandwich panels were also made with neat polyurethane foam without having any nanoparticle infusion.

\subsection{Dispersion of Nanoparticles into Liquid Polyurethane.} The steps used for dispersion of nanoparticles in liquid foam are shown in Figure 1. The liquid foam has two parts: part A (Diphenylmethane Diisocyanate) and part B (Fluorocarbon blown Polyol). Part A was selected for infusion of nanoparticles since it is less reactive than part B. Carbon nanofibers (CNFs) were first measured to have $1 \%$ by weight of partA plus part-B (step 1). It was observed that beyond $1.0 \mathrm{wt} \%$ loading, agglomeration increased significantly and the cell structures were collapsing. In our earlier investigations [5, 11,20 ] nanoparticle loading also remained within $1-3 \mathrm{wt} \%$. The mixing was carried out in a Sonic Vibra Cell ultrasonic liquid processor (Ti-horn, $20 \mathrm{kHz}, 100 \mathrm{~W} / \mathrm{cm}^{2}$ ) for about 30 minutes at $5^{\circ} \mathrm{C}$ temperature (step 2 ). At this time it was visually observed that nanoparticles were uniformly dispersed in Part-A. We varied the sonication parameters time, frequency, and intensity many times to come up with 30 minutes, $20 \mathrm{kHz}$, and $100 \mathrm{~W} / \mathrm{cm}^{2}$, respectively as optimum parameters for the system. After each trial, foam was made and looked under SEM to check the cell structures-if they were broken or collapsed, parameters were changed until we came up with the best possible cell structure. In order to avoid temperature rise during sonication, external cooling was applied for the entire period of irradiation. External cooling was applied through an NESLAB RTE Series refrigerated bath. After infusion of nanoparticles, the modified Part-A was mixed with Part-B at a ratio of $48: 52$ by weight using a mechanical stirrer at $2500 \mathrm{rpm}$ for about $30 \mathrm{~s}$ (step 3). The mixture was then cast into a mildly preheated steel rectangular mold. After about 8-9 hours, the cast foam (step 4) was demolded and postcured for about 20 minutes at $80^{\circ} \mathrm{F}$. The density of the foam in both categories was measured to be around $0.08 \mathrm{~g} / \mathrm{cc}$.

2.2. Sandwich Fabrication. CIRTM process was employed to fabricate the sandwich panels. Both the top and bottom face sheets were infused simultaneously during the CIRTM process. A schematic of the co-injection process is shown in Figure 2. Dry fabric preforms with required orientations were first laid out on the top of a flat aluminum tool. The fabric used in this investigation was plane weave S2-Glass fibers. Three layers of fabrics were used for each face sheet. The core was then placed on the top of the bottom face sheet fabrics, and upon which the preforms for the top face sheets were stacked. Two types of core materials were used during the fabrication; one was neat polyurethane, and the other was dispersed with CNF. After stacking, infusion lines were installed and the assembly was vacuum bagged. Before infusion the system was debulked for several hours. SC-15 epoxy resin (Part-A: epoxy, Part-B: Hardener, Alkyl Polyamine) manufactured by Applied Poleramic, Inc. was used in this study due to its low viscosity (300 cps) and longer 


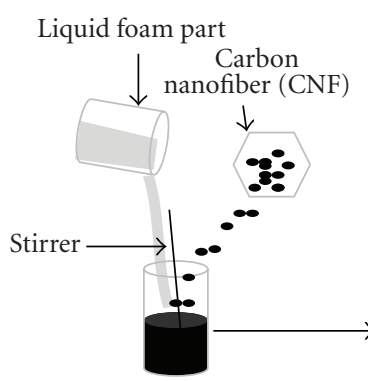

(a)

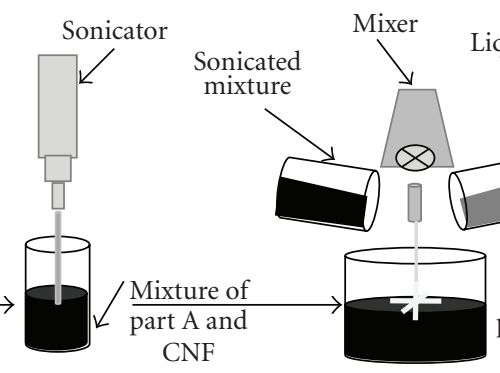

(b)

(c)
Liquid foam part-B

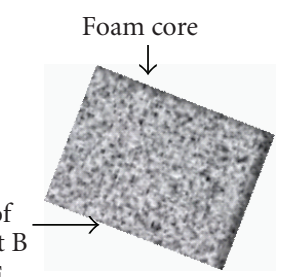

(d)

FIGURE 1: Schematic of manufacturing of nanophased PU foam: (a) step 1; (b) step 2; (c) step 3; (d) step 4.

TABLE 1: Materials used for sandwich construction.

\begin{tabular}{|c|c|c|c|c|}
\hline \multicolumn{3}{|c|}{ Face sheet (skin) } & \multicolumn{2}{|c|}{ Core materials } \\
\hline & Fiber & Resin & Foam & Nanoparticles(CNF) \\
\hline No. of layer 3 & S-2 Glass $240 \mathrm{~F}$ & Epoxy SC-15 & $\begin{array}{l}\text { Polyisocyanurate } \\
\text { density } 80 \mathrm{Kg} / \mathrm{m}^{3}\end{array}$ & $\begin{array}{l}\text { Purity: } 95 \% \text {, } \\
\text { density: } 1.95 \mathrm{~g} / \mathrm{cm}^{3} \text {, } \\
\text { diameter: } 70-200 \mathrm{~nm} \text {, } \\
\text { length: } 50-100 \mu \mathrm{m}\end{array}$ \\
\hline
\end{tabular}

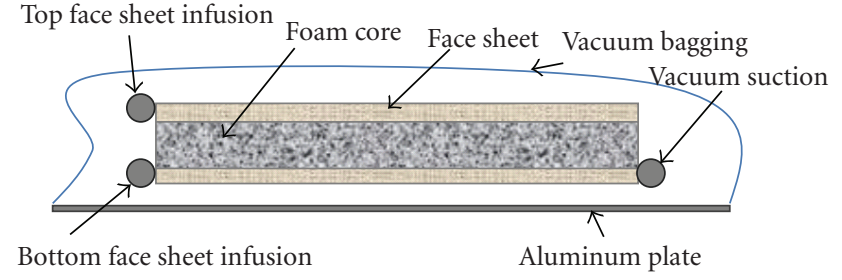

Figure 2: Schematic of co-injection resin transfer molding (CIRTM) process.

pot life (6 hours). After the resin infusion, the vacuum was kept on until the complete cure took place. No additional adhesives were used for the skin-core bonding, since it developed during the cure process. It is to be noted here that the surfaces of the nanophased foams had to be sanded prior to setting them up in the CIRTM mold. This allowed better adhesion between the core and the skin. Several panels were fabricated in this manner and were machined for shear characterization.

\section{Experimental Procedure}

3.1. Quasistatic Shear Tests. Several test coupons of neat and nanophased polyurethane foam sandwich specimens of dimension $40 \mathrm{~mm} \times 160 \mathrm{~mm}$ were cut from $12.5 \mathrm{~mm}$ thick panels, using a diamond-coated steel blade, as per ASTM C273-61 standard test method. The specimen was bonded between the two parallel loading steel plates as shown in the test set-up in Figure 3(a) which shows the schematic of the shear fatigue test fixture. The arrows indicate the

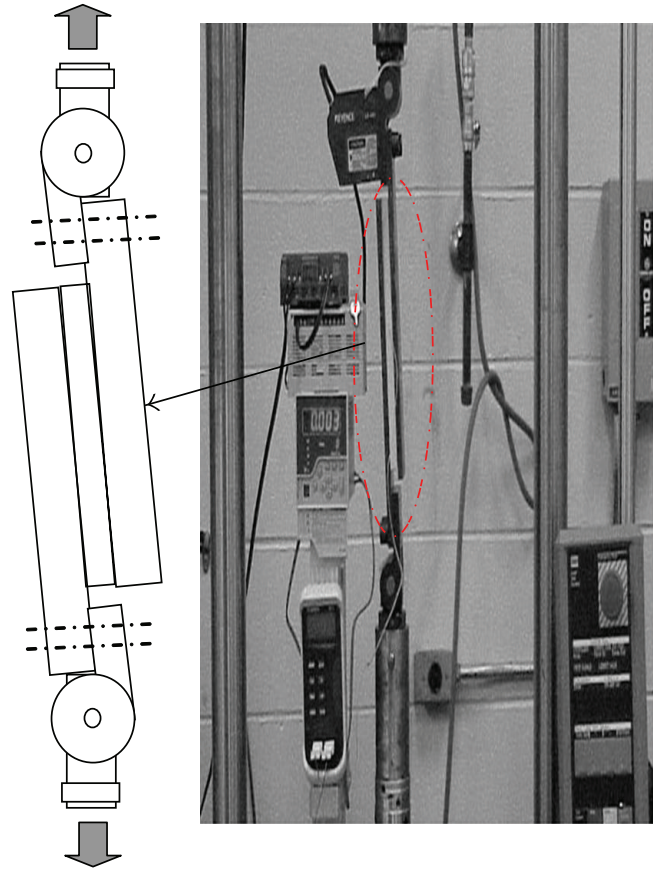

(a)

(b)

Figure 3: (a) Schematic of shear text fixture. (b) Photograph showing experimental setup.

direction of loading. The steel plates were truly parallel since a small deviation in parallelism of the loading plates can cause considerable errors in the calculation of the shear strength and shear modulus. A two-part epoxy, Hysol EA 9309.3 NA was used as the adhesive to bond the sandwich 
TABLE 2: Quasi-static shear test results.

\begin{tabular}{|c|c|c|c|}
\hline Property & Neat Polyurethane Foam Sandwich & 1\% CNF Polyurethane Foam sandwich & \% Improvement \\
\hline \multirow{4}{*}{ Shear Strength (MPa) } & 0.55 & 0.83 & \multirow{4}{*}{+33} \\
\hline & 0.64 & 0.81 & \\
\hline & 0.66 & 0.78 & \\
\hline & Ave.: $0.61 \pm 0.014$ & Ave. : $0.81 \pm 0.02$ & \\
\hline \multirow{4}{*}{ Shear Modulus (Mpa) } & 11.7 & 13.7 & \multirow{4}{*}{+19} \\
\hline & 11.9 & 14.9 & \\
\hline & 12.4 & 14.4 & \\
\hline & Ave. : $12.0 \pm 0.35$ & Ave. : $14.3 \pm 0.32$ & \\
\hline
\end{tabular}

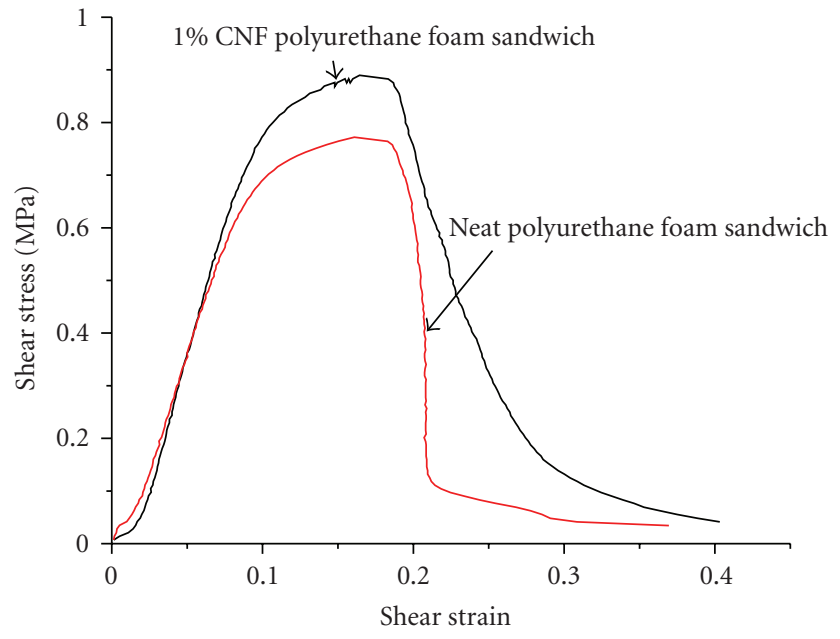

FIGURE 4: Stress-Strain curves for pure and nanophased foam sandwich.

samples to the steel plates. The epoxy was allowed to cure at room temperature for a minimum of 48 hours prior to testing. The fixture was installed in a servo hydraulic testing machine (MTS) fitted with a $100 \mathrm{kN}$ load cell as shown in Figure $3(\mathrm{~b})$. The tests were conducted at room temperature in displacement control mode at a cross-head speed of $1.27 \mathrm{~mm} / \mathrm{min}$. A Keyence laser displacement unit coupled to an $\mathrm{RD}-50 \mathrm{R}$ controller was installed (Figure (3b)) to measure the sliding movement of the loading plates relative to each other in the direction parallel to the loading plates.

The shear stress, $\tau$, is given by

$$
\tau=\frac{P}{L b},
$$

where $P$ is the load on the specimen, $L$ is the length of the specimen, and $b$ is its width. The shear strain, $\gamma$, is

$$
\gamma=\frac{r}{c}
$$

where $r$ is the displacement of one loading plate with respect to the other and, $c$, denotes the thickness of the core.
3.2. Shear Fatigue Tests. Shear fatigue tests were performed in accordance to ASTM 394-62 at room temperature under load control on the sandwich specimens at a load ratio of $R=$ $\left|P_{\min }\right| /\left|P_{\max }\right|=0.1$, using an MTS machine at a frequency of $3 \mathrm{~Hz}$. The runout cycle number was set at $10^{6}$ cycles. Fatigue data for a minimum of three specimens in each category of sandwich composites were generated at stress levels of $90 \%, 80 \%, 70 \%, 60 \%$, and $50 \%$ of the ultimate static shear strength.

3.3. Microscopic Analysis. Virgin surfaces were examined in a JEOL JSM 5800 scanning electron microscope. The specimens were glued to an aluminum base and coated with gold to prevent charge build-up by the electrons absorbed by the specimen. Microstructural analysis was performed on both neat and nanophased polyurethane foams.

\section{Results and Discussion}

4.1. Quasi-Static Shear Tests. Quasi-static shear tests were conducted primarily to obtain strength values for the fatigue tests. Load was applied to the neat and nanophased sandwich specimens via the steel plates as shown in Figure 3(b). The laser displacement unit recorded displacement of the moving steel plate relative to the fixed plate. This displacement was used to calculate the shearing strain, $\gamma$. Figure 4 shows representative stress-strain $(\tau-\gamma)$ curves for neat and nanophased sandwiches. Shear strength of nanophased foam as seen in Figure 4 was higher than that of neat. At the initial stage of loading small cracks were noticed in the core near the edge of the specimen. As the loading continued, the specimen elongated, small cracks coalesced into a dominant crack, and kinked into the core. Crack formation and propagation were identical with both categories of foams, but elongation with nanophased foam was higher. In the next sequence, rapid shearing of the core occurred and the specimen failed at the sub-interface section and also diagonally across the thickness of the core. Nanophased foam core sandwich demonstrated more ductile behavior than neat sandwich. This ductility is evident by the longer shear deformation region for nanophased sandwich seen in Figure 4. The large difference in the shear elongation clearly demonstrates that nanophased foam core has higher resistance to shear failure. 
High shear deformation with the nanophased foam is due to dissipation of energy at multiple sites created by CNF/PU interfaces. Polymer chemistry and kinetics are different at these interfaces and can be viewed as nanoscale defects in the polymer. Energy at crack tips can be easily dissipated into these defects attributing an effective energy absorption feature to the nanocomposites.

Shear strength and modulus data for quasi-static tests are shown in Table 2. Improvement in strength and modulus were approximately 33\% and 19\% higher than those of the neat foam sandwiches. An approximation of the area under the curves in Figure 4 suggests that the energy absorption capability of nanophased foam sandwich is almost 30\% more than that of the neat foam sandwich.

The crack propagation in the core during quasi-static loading was very similar to what was observed earlier with PVC foams [4]. A schematic of the core shear process is shown in Figure 5. First, crack initiated at the free edge in the uppermost section of the specimen adjacent to the core-skin interface. The crack then propagated parallel to the plate for a short distance, after which it kinked into the core moving diagonally towards the opposite end. This diagonal shearing event was the final failure mode in both categories of sandwich specimens. In few specimens, free-edge effects occurred, that is, the core tore apart from the skin at the free ends in the upper corners.

4.2. Fatigue Tests. Shear fatigue data for both neat and nanophased sandwich composites are shown in Table 3. S$\mathrm{N}$ (stress versus number of cycles) diagram for the fatigue tests is shown in Figure 6 The stress axis is normalized with ultimate shear strength. Data shown in the S-N diagram are the average values from Table 3 . Under constant amplitude loading many engineering materials exhibit a plateau in the stress life plot typically beyond $10^{6}$ cycles, which is also true in this case. The fatigue limit is seen to be about $55 \%$ of the ultimate strength for the nanophased specimen while it is $50 \%$ for neat specimen. It is seen in Figure 6 and in Table 3 that at each stress level, the number of cycles to failure for nanophased foam was significantly higher than that of neat specimen. The failure process in both the nanophased and neat sandwiches was similar to that of PVC foam sandwich composites studied by one of the authors [4]. Fatigue failure modes are shown in Figure 7. Small cracks first appeared near the core-skin interface that coalesced into several larger cracks and progressed along the interface. After propagating for a relatively short distance, these larger cracks as seen in Figure 7 kinked into the core and traversed through the thickness of the core. This suggests that during fatigue as well as in static loading, the weakest region in a sandwich composite is the core-skin interface region which is prone to failure at the initial stage of the loading. These minute cracks coalesce into one or many major cracks depending on the type of loading. If it is quasi-static, usually there is only one major crack. However in case of fatigue loading the number of major cracks is several. During quasi-static loading, the major crack kinks into the core at a sharp angle and diagonally crosses the entire thickness of the core.

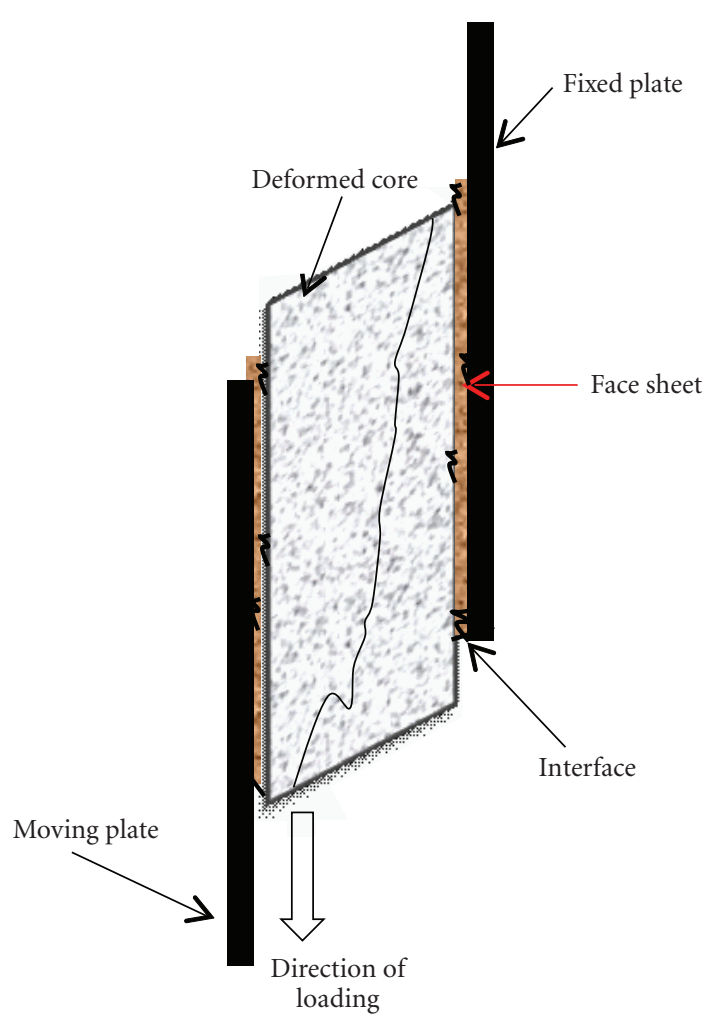

FIGURE 5: Schematic of crack propagation during static loading.

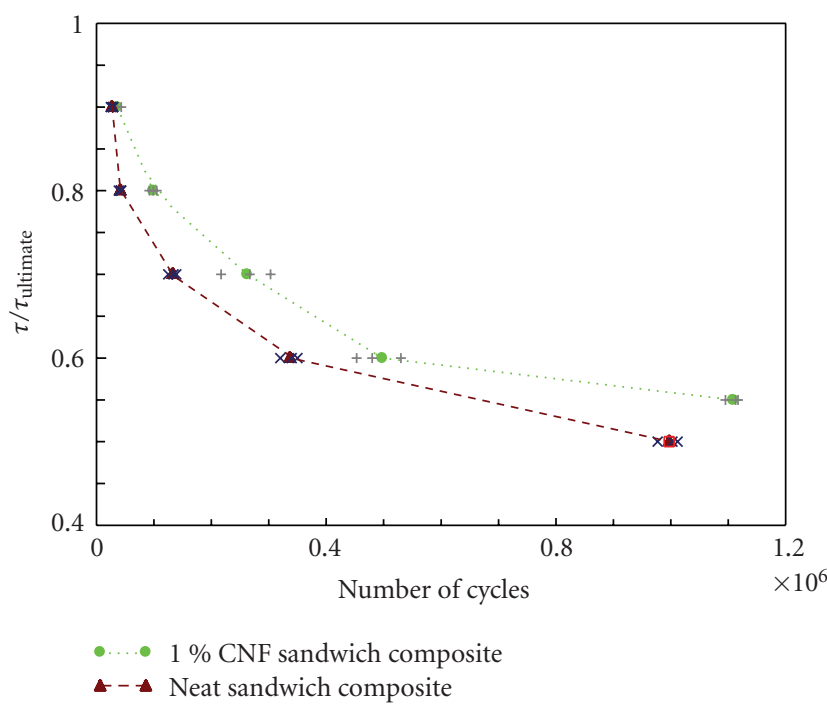

FIGURE 6: S-N curves for neat and nanophased specimens. Stress ratio $R=0.1$ and frequency $=3 \mathrm{~Hz}$.

During fatigue the scenario is somewhat different-large cracks kink into the core at multiple places and propagate at about $20-40^{\circ}$ angle. Cracks kinking into the core in fact signals the final failure event as the core shear process is very quick. As seen in Figure 7, some of the shear cracks reach the interface on the opposite side depending on the energy available at the crack tip and resistance offered by the embedded nanoparticles. 


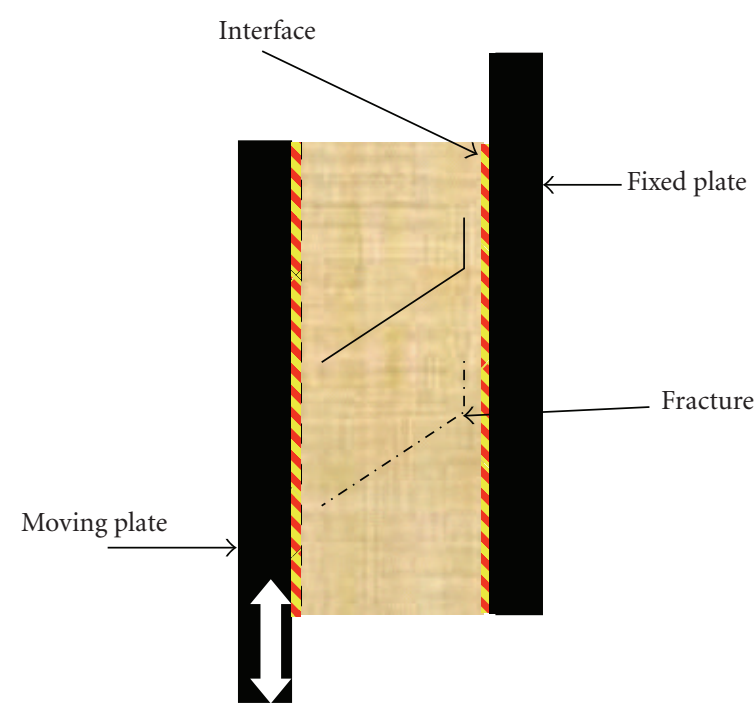

(a)

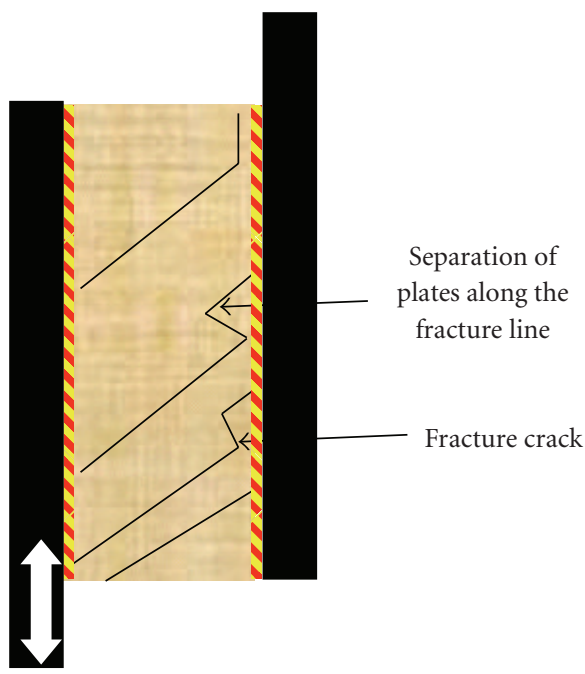

(b)

FIGURE 7: (a) Schematic of crack formation in the core and (b) schematic showing the line along which final shearing occurs.

TABLE 3: Fatigue test data for neat and 1\% CNF sandwich composites.

\begin{tabular}{|c|c|c|c|c|c|}
\hline \multirow[t]{2}{*}{ Material } & \multicolumn{5}{|c|}{ Number of Cycles $\times 10^{6}$} \\
\hline & $90 \% \tau_{\text {ultimate }}$ & $80 \% \tau_{\text {ultimate }}$ & $70 \% \tau_{\text {ultimate }}$ & $60 \% \tau_{\text {ultimate }}$ & $50 \% \tau_{\text {ultimate }}$ \\
\hline \multirow{4}{*}{ Neat PUF Sandwich Composite } & 0.025 & 0.043 & 0.125 & 0.32 & 0.977 \\
\hline & 0.028 & 0.039 & 0.134 & 0.34 & 1.003 \\
\hline & 0.03 & 0.04 & 0.14 & 0.35 & 1.01 \\
\hline & Avg. : $0.027 \pm 0.002$ & Avg. : $0.041 \pm 0.002$ & Avg. : $0.13 \pm 0.01$ & Avg. : $0.37 \pm 0.02$ & Avg. : $1.0 \pm 0.02$ \\
\hline \multirow{4}{*}{ 1\% CNF PUF Sandwich Composite } & 0.029 & 0.092 & 0.217 & 0.453 & 1.095 \\
\hline & 0.036 & 0.099 & 0.267 & 0.48 & 1.117 \\
\hline & 0.043 & 0.105 & 0.303 & 0.53 & 1.113 \\
\hline & Ave. : $0.04 \pm 0.01$ & Avg.: $0.10 \pm 0.01$ & Avg. : $0.26 \pm 0.04$ & Avg. : $0.49 \pm 0.04$ & Avg. : $1.11 \pm 0.01$ \\
\hline
\end{tabular}

4.3. SEM Analysis. To investigate the dispersion of nanoparticles and their effect on the foam microstructures, SEM analyses were carried out on both neat and nanophased foam as shown in Figures 8(a)-8(d). It was observed that as-received CNFs were agglomerated due to high surface energy as shown in Figure 8(a). Since the length of CNF is in the order of micron, it is possible to observe individual CNF-dimensional parameters. The diameter of CNF was measured to be about $200 \mathrm{~nm}$, which agrees with the data sheet [38]. Embedded CNFs in the cell edges are shown in Figure $8(\mathrm{~b})$. Figure $8(\mathrm{~b})$ also indicates that the CNFs were well separated and dispersed. The micrographs (c) and (d) show that both neat and nanophased foams have a fairly uniform distribution of regular cells. As seen in these figures, cell edges and walls are distinctly visible with almost uniform cell structures throughout. It is observed in the micrographs that CNF nanoparticle has somewhat different effect on the microstructure of the cell as it was observed in earlier studies $[5,11,20]$. In the present case the size of the cell does not change whereas the shape of the cell has changed significantly-from spherical to pentagon or hexagonal shape. It is well known that closed cell foam derives its strength from its edges, walls, faces, and the entrapped gas. Nanophased core will provide more resistance to crack propagation due to its hexagonal shape, relatively thicker edges, and walls as seen in Figure $8(\mathrm{~d})$. It is quite possible that as the resin gets filled into the partially opened cells, it soaks the cell walls and edges up to a certain depth. When the resin is cured, these soaked cells become stronger than the regular dry cells just underneath. A sub-interface is therefore created between these so-called soaked and dry cells, which are apparently weaker than the actual coreskin interface mentioned earlier. It is indicated in earlier studies $[11,20]$ that nanoparticle acts as a catalyst during the foaming process and controls the rate of $\mathrm{CO}_{2}$ generation, which in turn affects the cell wall and edge thicknesses. It is believed that more resins are absorbed in thicker edges and walls during the fabrication of sandwich composites. This will make the soaked region relatively stronger and consequently delay the initiation of cracks in the nanophased foams during fatigue. In particular, two phenomena will dominate the failure of the core during shear fatigue: (i) cell stretching in the loading direction which gives rise to initial interface cracks and (ii) kinking of the interface 


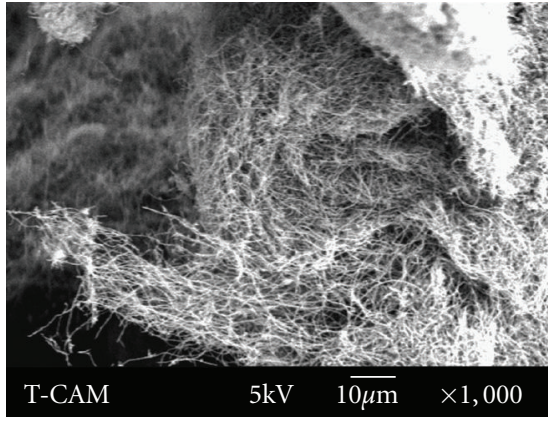

(a)

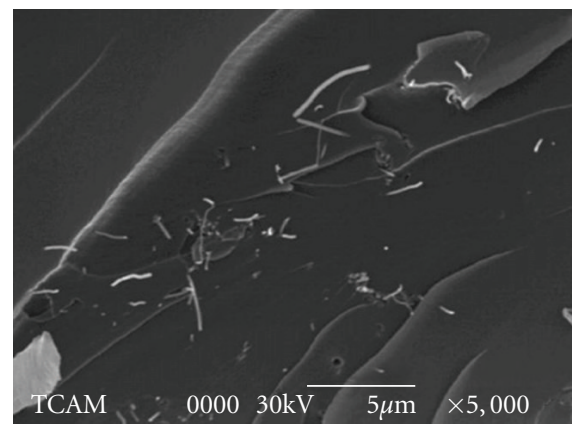

(b)

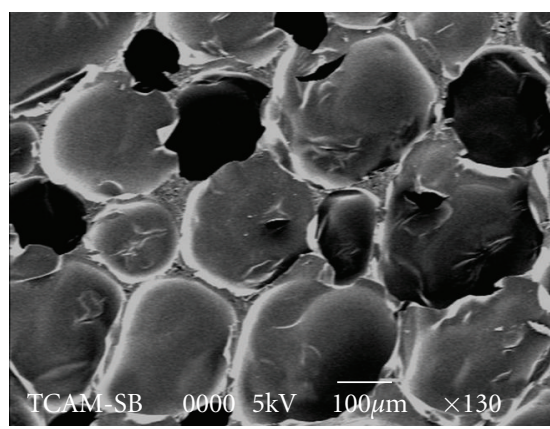

(c)

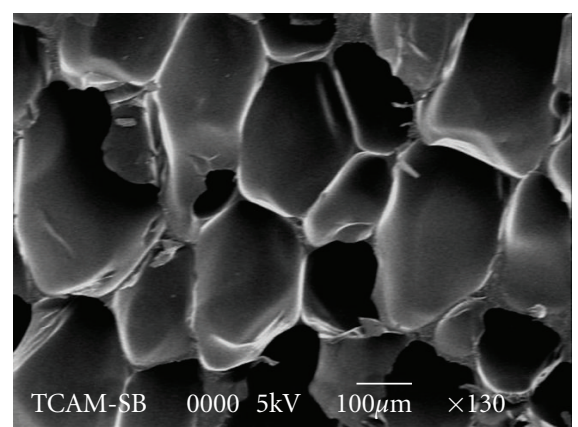

(d)

FIGURE 8: Micrographs of (a) as-received CNFs (b) embedded CNFs in PUF (c) cell structure of neat PUF (d) cell structure of PUF with $1.0 \mathrm{wt} \% \mathrm{CNFs}$ cracks into the core. Both of these phenomena are delayed by the nanophased foam as they possess higher strength and modulus. As a result nanophased sandwich composites demonstrate higher fatigue performance.

\section{Summary}

(1) It is shown that shear strength and modulus of nanophased sandwich composites can be increased by about $30 \%$ by reinforcing the polyurethane core material with $1 \mathrm{wt} \%$ loading of carbon nanofibers (CNFs)

(2) Significant improvements have also been observed during fatigue loading under shear. In an average sense fatigue limit (i.e., stress level to survive more than 1 million cycles) of nanophased sandwich composites was found to be around $55 \%$ of the ultimate shear strength as opposed to $50 \%$ in case of neat foam. On a specific note, for example, at $57 \%$ of $\tau_{\text {ultimate }}$, nanophased sandwich would survive 400,000 cycles more than its neat counterpart.

(3) It is observed that quasi-static shear failure is mostly governed by a single shear crack diagonally traversing through the core. On the other hand in case of shear fatigue, failure is due to multiple cracks across the thickness of the core. In both cases, cracks initially appear at the coreskin interface, propagate for a short distance along the interface, and then kink into the core signaling the final failure event.

(4) Embedded nanoparticles seem to modify the cell structures, offer resistance to crack propagation, and delay the kinking of interface cracks into the core.

\section{Acknowledgment}

The authors would like to thank the Office of Naval Research (ONR) (Grant no. N00014-06-1-0696) and the National Science Foundation, (NSF) (Grant no. HRD-976871) for supporting this research.

\section{References}

[1] D. Zenkert, An Introduction to Sandwich Construction, EMAS, Solihull, UK, 1995.

[2] E. E. Gdoutos, I. M. Daniel, and K. A. Wang, "Failure of cellular foams under multiaxial loading," Composites Part A, vol. 33, no. 2, pp. 163-176, 2002.

[3] N. Kulkarni, H. Mahfuz, S. Jeelani, and L. A. Carlsson, "Fatigue crack growth and life prediction of foam core sandwich composites unders flexural loading," Composite Structures, vol. 59, no. 4, pp. 499-505, 2003.

[4] T. Thomas, H. Mahfuz, K. Kanny, and S. Jeelani, "Dynamic compression of sandwich composites at sub-ambient temperatures," Journal of Composite Materials, vol. 38, no. 8, pp. 641653, 2004.

[5] H. Mahfuz, V. K. Rangari, M. S. Islam, and S. Jeelani, "Fabrication, synthesis and mechanical characterization of nanoparticles infused polyurethane foams," Composites Part $A$, vol. 35, no. 4, pp. 453-460, 2004. 
[6] K. Kanny, H. Mahfuz, L. A. Carlsson, T. Thomas, and S. Jeelani, "Dynamic mechanical analyses and flexural fatigue of PVC foams," Composite Structures, vol. 58, no. 2, pp. 175-183, 2002.

[7] A. Shipsha, M. Burman, and D. Zenkert, "Interfacial fatigue crack growth in foam core sandwich structures," Fatigue and Fracture of Engineering Materials and Structures, vol. 22, no. 2, pp. 123-131, 1999.

[8] E. Reynaud, C. Gauthier, and J. Perez, "Nanophases in polymers," Revue de Metallurgie, vol. 96, no. 2, pp. 169-176, 1999.

[9] C. L. Wu, M. Q. Zhang, M. Z. Rong, and K. Friedrich, “Tensile performance improvement of low nanoparticles filledpolypropylene composites," Composites Science and Technology, vol. 62, no. 10-11, pp. 1327-1340, 2002.

[10] H. Mahfuz, N. Chisholm, and S. Jeelani, "Quasi-static and high strain rate response of nano-featured carbon/epoxy composites," in Proceedings of the ASME Winter Annual Meeting, New Orleans, La, USA, November 2002.

[11] H. Mahfuz, V. K. Rangari, M. S. Islam, and S. Jeelani, "Fabrication, synthesis and mechanical characterization of nanoparticles infused polyurethane foams," Composites Part A, vol. 35, no. 4, pp. 453-460, 2004.

[12] T. J. Pinnavaia and F. W. Beall, Polymer-Clay Nanocompostes, Wiley Series in Polymer Science, John Wiley \& Sons, Chichester, UK, 2000.

[13] M. Alexandre and Ph. Dubois, "Polymer-layered silicate nanocomposites: Preparation, properties and uses of a new class of materials," Materials Science and Engineering $R$, vol. 28, no. 1, pp. 1-63, 2000.

[14] C. Zilg, R. Thomann, R. Mülhaupt, and J. Finter, "Polyurethane nanocomposites containing laminated anisotropic nanoparticles derived from organophilic layered silicates," Advanced Materials, vol. 11, no. 1, pp. 49-52, 1999.

[15] Y. Kojima, A. Usuki, M. Kawasumi, et al., "Mechanical properties of nylon 6-clay hybrid," Journal of Materials Research, vol. 8, no. 5, pp. 1185-1189, 1993.

[16] P. B. Messersmith and E. P. Giannelis, "Synthesis and barrier properties of poly( $\varepsilon$-caprolactone)-layered silicate nanocomposites ," Journal of Polymer Science Part A, vol. 33, no. 7, pp. 1047-1057, 1995.

[17] Y. Kojima, K. Fukumori, A. Usuki, A. Okada, and T. Kurauchi, "Gas permeabilities in rubber-clay hybrid," Journal of Materials Science Letters, vol. 12, no. 12, pp. 889-890, 1993.

[18] P. Kelly, A. Akelah, S. Qutubuddin, and A. Moet, "Reduction of residual stress in montmorillonite/epoxy compounds," Journal of Materials Science, vol. 29, no. 9, pp. 2274-2280, 1994.

[19] E. Andrews, W. Sanders, and L. J. Gibson, "Compressive and tensile behavior of aluminum foams," Journal of Materials Science and Engineering, vol. 270, pp. 113-124, 1998.

[20] H. Mahfuz, M. F. Uddin, V. K. Rangari, M. C. Saha, S. Zainuddin, and S. Jeelani, "High strain rate response of sandwich composites with nanophased cores," Applied Composite Materials, vol. 12, no. 3-4, pp. 193-211, 2005.

[21] F. Pervin, Y. Zhou, V. K. Rangari, and S. Jeelani, "Testing and evaluation on the thermal and mechanical properties of carbon nano fiber reinforced SC-15 epoxy," Materials Science and Engineering A, vol. 405, no. 1-2, pp. 246-253, 2005.

[22] M. E. Kabir, M. C. Saha, and S. Jeelani, "Effect of ultrasound sonication in carbon nanofibers/polyurethane foam composite," Materials Science and Engineering A, vol. 459, no. 1-2, pp. 111-116, 2007.
[23] M. L. Lake and J. M. Ting, "Vapor grown carbon fiber composites," in Carbon Materials for Advanced Technologies, T. D. Burchell, Ed., pp. 139-167, Pergamon Press, Oxford, UK, 1999.

[24] K. P. De Jong and J. W. Geus, "Carbon nanofibers: catalytic synthesis and applications," Catalysis Reviews-Science and Engineering, vol. 42, no. 4, pp. 481-510, 2000.

[25] Y. Zheng, Y. Zheng, and R. Ning, "Effects of nanoparticles SiO on the performance of nanocomposites," Materials Letters, vol. 57, no. 19, pp. 2940-2944, 2003.

[26] B. Wetzel, F. Haupert, and M. Q. Zhang, "Epoxy nanocomposites with high mechanical and tribological performance," Composites Science and Technology, vol. 63, no. 14, pp. 20552067, 2003.

[27] W. L. M. Nyborg, "Acoustic streaming," in Physical Acoustics, IIB, W. P. Mason, Ed., vol. 355, Academic Press, Boston, Mass, USA, 1965.

[28] B. E. Noltingk and E. A. Neppiras, "Cavitation produced by ultrasonics," Proceedings of the Physical Society. Section B, vol. 63, no. 9, pp. 674-685, 1950.

[29] K. S. Suslick, Ed., Ultrasound: It's Chemical, Physical, and Biological Effects, Wiley-VCH, Vancouver, Canada, 1988.

[30] O. Abramov, Ultrasound in Liquid and Solid Metals, vol. 289, CRC Press, Boca Raton, Fla, USA, 1994.

[31] K. S. Suslick, Y. Didenko, M. M. Fang, et al., "Acoustic cavitation and its chemical consequences," Philosophical Transactions of the Royal Society A, vol. 357, no. 1751, pp. 335353, 1999.

[32] S. Torquato, L. V. Gibiansky, M. J. Silva, and L. J. Gibson, "Effective mechanical and transport properties of cellular solids," International Journal of Mechanical Sciences, vol. 40, no. 1, pp. 71-82, 1998.

[33] M. C. Shaw and T. Sata, "The plastic behaviour of cellular materials," International Journal of Mechanical Sciences, vol. 8, pp. 469-478, 1966.

[34] C. M. Ford and L. J. Gibson, "Uniaxial strength asymmetry in cellular materials: an analytical model," International Journal of Mechanical Sciences, vol. 40, no. 6, pp. 521-531, 1998.

[35] R. M. Christensen, "Mechanics of cellular and other lowdensity materials," International Journal of Solids and Structures, vol. 37, no. 1-2, pp. 93-104, 2000.

[36] M. R. Patel and I. Finnie, "Structural features and mechanical properties of rigid cellular plastics," Journal of Materials Chemistry, vol. 5, no. 4, pp. 909-932, 1970.

[37] M. Zawlawsky, "Multiaxial stress studies ion rigid polyurethane foam," Experimental Mechanics, vol. 13, pp. 70-76, 1973.

[38] "Material data sheet: PUR240," Utah Foam, 3609 South 700 West, Salt Lake City, UT 84119, USA. 

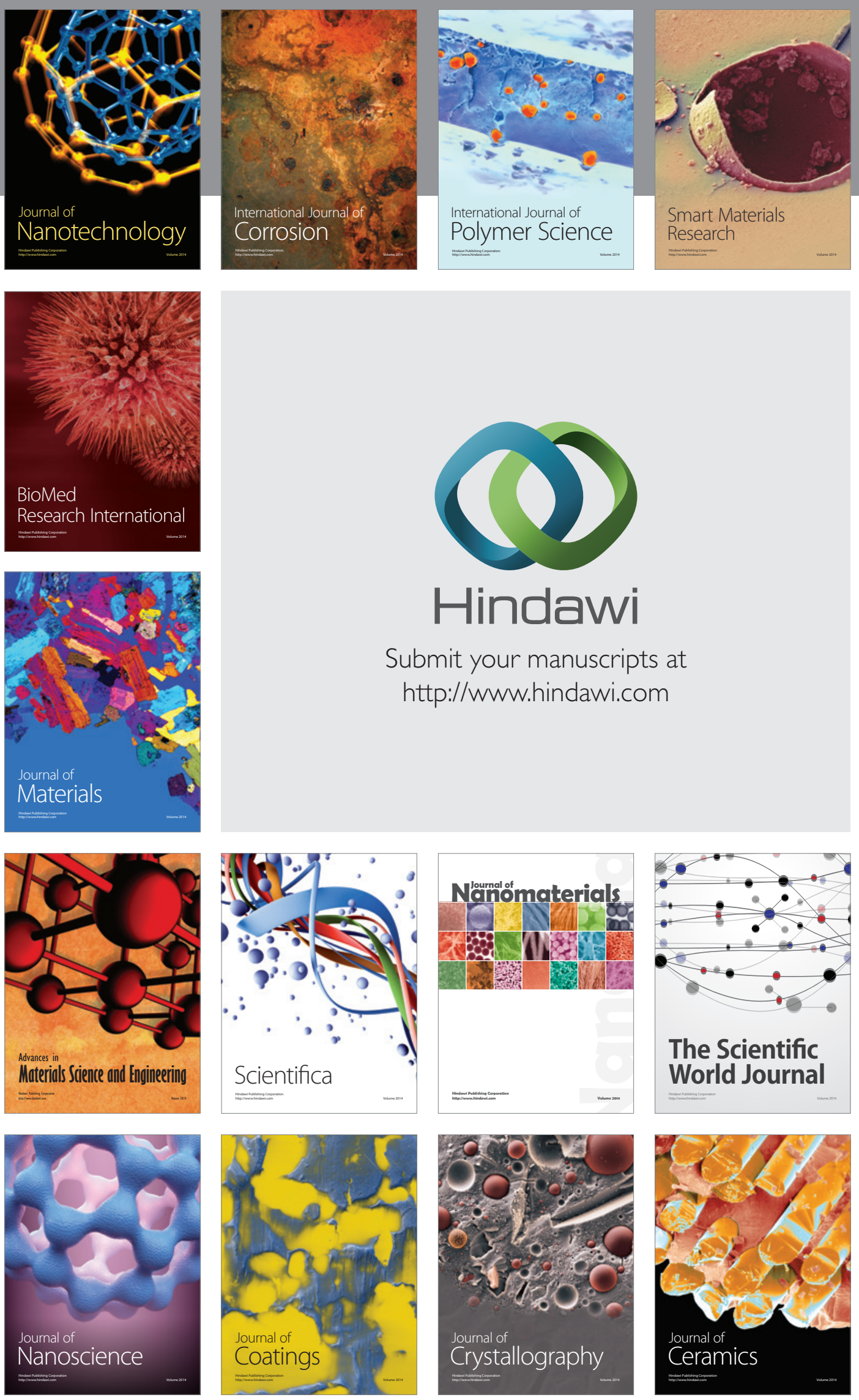

The Scientific World Journal

Submit your manuscripts at

http://www.hindawi.com

\section{World Journal}

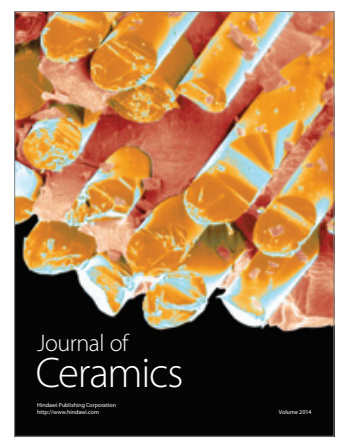

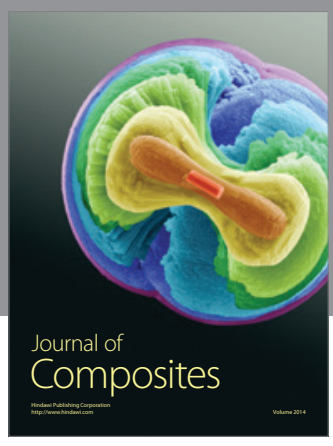
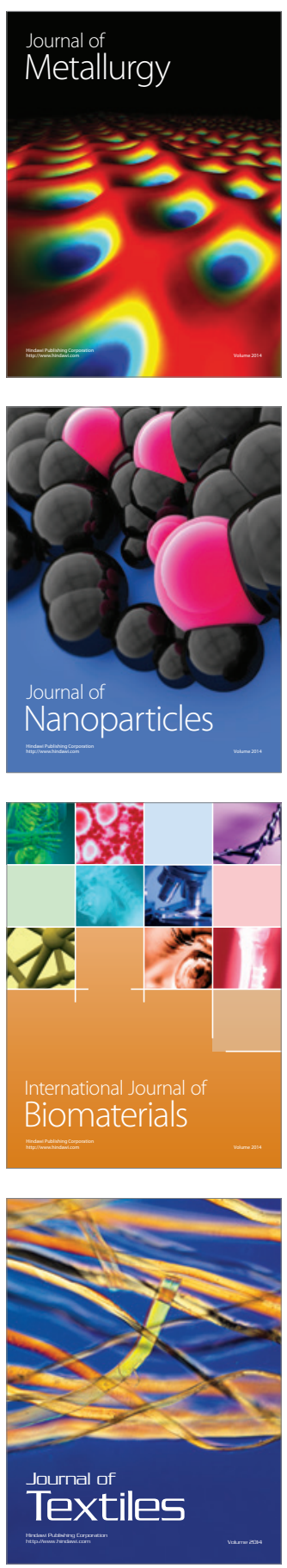